\title{
MEDINDO O \\ CAPITAL INTELECTUAL
}

\author{
Luiz Antonio Joia \\ Engenheiro pelo Instituto Militar de Engenharia, \\ Mestre e Doutor em Engenharia de Produção pela COPPE/UFRJ \\ e Professor Adjunto da FGV-EBAP. \\ E-mail: luizjoia@fgv.br
}

\section{RESUMO}

Pesquisas vêm sendo conduzidas a fim de definir um caminho confiável e factível para avaliarem-se os ativos intangíveis de uma empresa. Vários modelos foram desenvolvidos, embora ainda haja problemas a resolver. Neste artigo, apresenta-se um modelo heurístico que considera o vínculo entre o Capital Intelectual e a Estratégia Empresarial, de modo que se avaliem os ativos intangíveis de empresas, ao longo do tempo, segundo a estratégia de negócios implantada. Como estudo de caso, o modelo é aplicado a uma empresa atuante na indústria de magnésio. Expõe-se, também, a "Armadilha da Defasagem de Tempo", mostrando-se os erros de concepção que surgem numa abordagem estática, ao invés de dinâmica, para valoração dos ativos intangíveis. Tendências futuras e algumas conclusões importantes nessa área são relatadas.

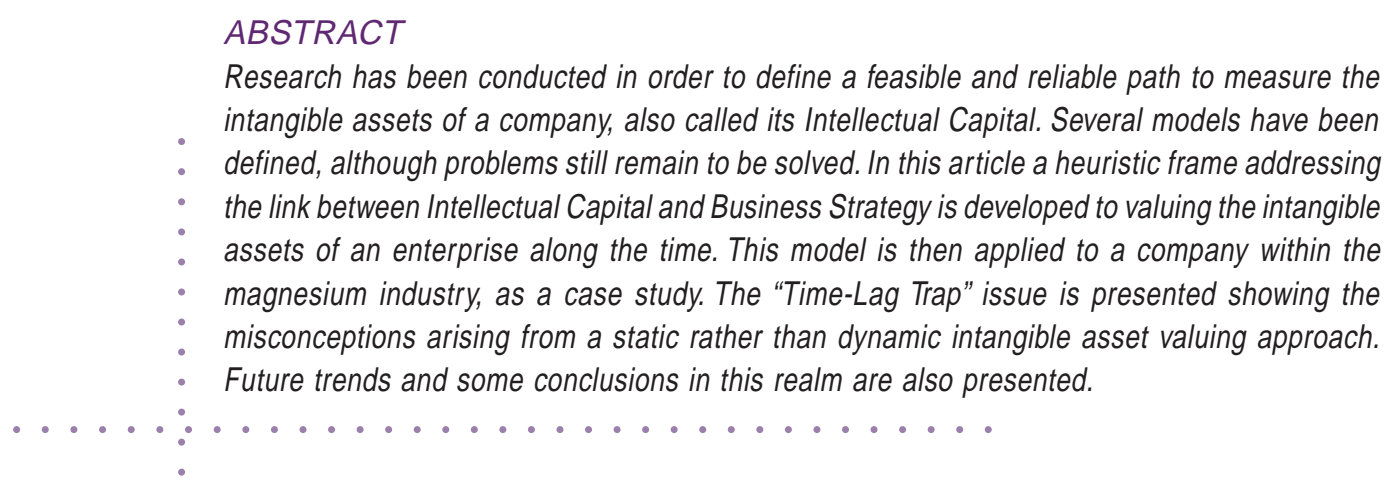

PALAVRAS-CHAVE: Capital Intelectual, Estratégia Empresarial, ativos intangíveis, avaliação de desempenho, economia do conhecimento.

KEY WORDS: Intellectual capital, business strategy, intangible assets, performance evaluation, knowledge economy. 


\section{INTRODUÇÃO}

A compreensão do conhecimento como uma arma estratégica para as corporações pode ser tudo, menos recente. Em 1945, Frederick Hayek apresentou uma pesquisa sobre o uso do conhecimento na sociedade (Hayek, 1945). Em 1962, em um trabalho criativo, Fritz Machlup, da Universidade de Princeton, produziu uma obra de oito volumes com o título geral Knowledge: its creation, distribution, and economic significance (Stewart, 1997). Nesse trabalho, concluiu-se, com base em dados de 1958, que $34,5 \%$ do produto nacional bruto dos Estados Unidos podiam ser alocados ao setor de informação. Em 1993, Peter Drucker analisou uma nova economia da informação e suas conseqüências (Drucker, 1993). Portanto, cada vez mais, a importância dos ativos intangíveis de uma corporação, e até mesmo os de países e também os de outras organizações - incluindo entidades sem fins lucrativos -, vem sendo destacada por acadêmicos, pesquisadores e executivos.

Várias publicações merecem ser mencionadas por seus próprios méritos, como The balanced scorecard, de Kaplan e Norton (Kaplan e Norton, 1996) e The valuation of intangible assets, preparado pela Arthur Andersen e The economist intelligence unit (Arthur Andersen and The economist intelligence unit, Special report $\mathrm{n}^{\circ} \mathrm{P} 254$, 1992). Chegou-se, entretanto, a uma conclusão em 1994, quando foi realizada uma reunião em Mill Valley para o estabelecimento de como o conhecimento de uma organização poderia ser medido. O conhecimento podia ser intangível, mas isso não significava que não poderia ser medido. Como se sabe, os mercados fazem isso quando avaliam as ações de algumas empresas baseadas no conhecimento, com valor bem acima do registrado em seus livros contábeis.

A nova economia do conhecimento já é uma realidade, indo contra a lei de Marshall dos retornos decrescentes e refutando que quanto mais se aplica em determinado recurso, mais o mesmo recurso é gerado e, portanto, mais valor esse recurso agrega ao produto final (Arthur, 1996).

Em 1995, a Skandia - a maior empresa de seguros e serviços financeiros da Escandinávia - divulgou seu relatório anual de Capital Intelectual, baseado em seu modelo Navigator (Edvinsson e Malone, 1997). Algumas outras empresas, como a Dow Chemical, o Canadian Imperial Bank of Commerce e a Posco, para citar apenas algumas, adentraram nessa nova era.

\section{ATIVOS CORPORATIVOS INTANGÍVEIS}

Neste artigo, será evitado lidar com valores absolutos, pois não tem utilidade alguma o estabelecimen- to de quanto soma em dólares o Capital Intelectual de determinada empresa. A relação de Valor de Mercado para Valor Contábil $(\mathrm{M} / \mathrm{C})$ será usada como um padrão eficaz para medir ativos intangíveis.

Com base em pesquisa realizada por Edvinsson e Malone (1997), Roos et al. (1997), Sveiby (1997) e Stewart (1997), propõe-se que se utilize neste artigo uma taxonomia para o capital corporativo.

Assume-se que:

VALOR DE MERCADO = VALOR CONTÁBIL + CAPITAL

INTELECTUAL

Essa equação mostra que o valor das ações tem uma porção tangível (valor contábil), além de uma componente intangível. Daí, supondo-se que o Capital Intelectual seja maior do que zero $(\mathrm{CI}>0)$, a razão Valor de Mercado/Valor Contábil é maior do que 1 (M/C > 1). Quanto mais conhecimento a empresa possuir, maior será o valor de $\mathrm{M} / \mathrm{C}$, como é demonstrado nos exemplos da Tabela 1, com valores de novembro de 1996 (Stewart, 1997):

Tabela 1 - Valores (M/C)

\begin{tabular}{|l|l|c|c|}
\hline Empresa & Valor de mercado & Valor contábil & M/C \\
\hline IBM & US\$ 70,7 bilhões & US\$ 16,6 bilhões & 4,25 \\
\hline Microsoft & US\$ 85,5 bilhões & US\$ 930 milhões & 91,93 \\
\hline
\end{tabular}

Como se pode ver, o mercado percebe na Microsoft um elemento de valor intangível muito maior do que na IBM. Alguns poderiam dizer que políticas diferentes de depreciação podem influenciar o cálculo do valor contábil. É um argumento válido e é o motivo pelo qual Tobin (1969) sugere o uso do custo de substituição, definindo-se $q$ como (Valor de Mercado)/(Custo de Substituição dos Ativos). O conceito de custo de substituição foi desenvolvido para contornar as políticas de depreciação diferenciadas utilizadas por contadores em todo o mundo. Se $q$ for maior do que 1 , o ativo vale mais do que o custo de substituí-lo, portanto é mais provável que a empresa procure adquirir mais ativos desse tipo.

Calcula-se, então, o Valor Contábil pela seguinte fórmula:

VALOR CONTÁBIL = CAPITAL MONETÁRIO + CAPITAL

FÍSICO

E o Capital Intelectual, anteriormente chamado de bens intangíveis pelos contadores, é calculado usando-se a fórmula abaixo:

CAPITAL INTELECTUAL = CAPITAL HUMANO +

CAPITAL ESTRUTURAL 
O Capital Humano não pertence à empresa, pois é conseqüência direta da soma das habilidades e especialidades de seus empregados. O Capital Estrutural pertence à empresa e pode ser negociado (pelo menos em teoria), sendo o ambiente real construído pela companhia para administrar e gerar seu conhecimento de forma adequada. É composto por todos os processos internos e externos que existem dentro da empresa e entre ela e seus outros parceiros (capital de processos); pelo capital de relacionamento, ligado aos fornecedores, clientes, prestadores de serviços e outros parceiros principais envolvidos; e pelo capital de inovação, uma conseqüência direta da cultura da empresa e de sua capacidade de criar conhecimento novo com base no conhecimento existente. Assim, a fórmula a seguir resume o que foi exposto acima:

CAPITAL ESTRUTURAL = CAPITAL DE PROCESSOS + CAPITAL de RELACIONAMENTO + CAPITAL DE INOVAÇÃO

Finalmente, a fórmula do Capital Intelectual pode ser apresentada completa:

CAPITAL INTELECTUAL = CAPITAL HUMANO + CAPITAL DE PROCESSOS + CAPITAL DE RELACIONAMENTO + CAPITAL DE INOVAÇÃO

A Figura 1 ilustra todos esses conceitos, mostrando os componentes do Capital Intelectual (os ativos intangíveis) em caixas cinzas, todos tendo a mesma importância para a empresa.

\section{METODOLOGIA}

A metodologia usada neste artigo deriva dos modelos existentes propostos por Edvinsson e Malone (1997), Roos et al. (1997), pelo NCI da Kellog School of Business na Northwestern University (Stewart, 1997), por Sveiby (1997), Klein (1998) e Winter (1998). Nesse último estudo, o conceito de modelo heurístico desenvolvido por Winter em seu artigo Knowledge and competence as strategic assets é amplamente utilizado. Como afirma Winter: "Um modelo heurístico corresponde a um grau de definição de problema que ocupa uma posição intermediária na seqüência entre uma lista longa e indiscriminada de coisas que podem importar de um lado e um modelo teórico de controle bastante elaborado do outro. Dentro de um modelo heurístico, há espaço para uma ampla gama de formulações mais específicas do problema mas também existe estrutura suficiente fornecida pelo próprio modelo para guiar e focalizar a discussão. Por outro lado, uma variedade rica de modelos heurísticos diferentes pode representar abordagens plausíveis para um problema apresentado" (Winter, 1998, p. 172-173).

Com base nessa formulação, a metodologia relatada é uma dentre muitas que ainda podem ser utilizadas em um futuro muito próximo e representa um esforço para superar o efeito de "paralisia por análise" (Ansoff, 1984) extremamente comum quando se lida com coisas intangíveis, levando a discussões intermináveis, e não a resultados práticos. Um modelo é bom não por causa do excesso de rigor que aplica a si mesmo, medido pelo número de variáveis levadas em consideração, mas, sim, pelo fato de modelar e expressar, ade-

Figura 1 - Taxonomia do Capital Intelectual

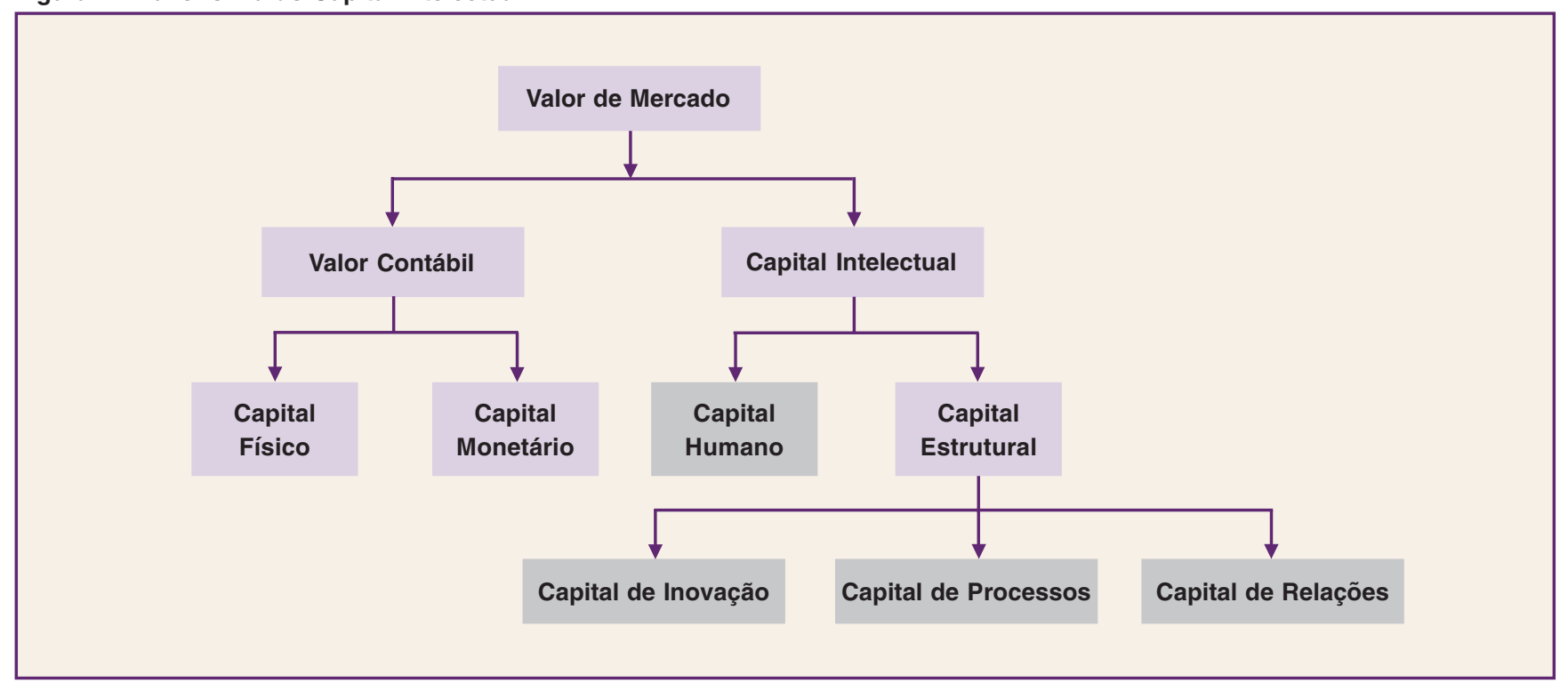


quadamente, a realidade que se enfrenta. A complexidade não é necessariamente sinônimo de bons resultados e é preciso ter-se alguma flexibilidade quando se lida com tópicos para os quais é necessário uma boa dose de senso crítico.

No artigo Knowledge as strategy (Earl, 1997), é possível inferir que a atribuição de valores ao Capital Intelectual Corporativo e seus componentes só vale a pena se houver ligação com a Estratégia Empresarial da empresa. Com base na Estratégia, é possível obter-se a declaração da missão da empresa e seus planos de ação abrangentes e específicos. Para calcular a intangibilidade, deve-se definir e classificar alguns indicadores de acordo com a taxonomia de Capital Intelectual indicada. O estrategista deve escolher os pesos associados a cada um desses indicadores. Todo o capital intangível pode, então, ser calculado pela combinação dos dados disponíveis para os indicadores e seus pesos.

A composição do Capital Intelectual como um todo é um exercício que tem sido entendido equivocadamente até agora. Edvinsson e Malone (1997) propõem que o Capital Intelectual seja a média aritmética de todos os principais componentes em jogo. Por outro lado, nossa correlação estatística mostra que se deve aplicar algum peso derivado da Estratégia Empresarial, para definir-se o Capital Intelectual como um todo. Isso é feito na metodologia relatada. Naturalmente, espera-se encontrar uma correlação bem grande entre os valores de Capital Intelectual e de mercado, à medida que o tempo avança. O Capital Intelectual, por si só, não tem valor. Ele deve ser entendido como uma forma de refinar a Estratégia Empresarial da empresa, oferecendo feedback positivo (Arthur, 1996). Na mesma medida, uma relação pobre entre taxas de Capital Intelectual e valores de mercado evidenciam, por definição, um modelo ruim ou dados unilaterais, como formulado por Roos et al. (1997). Para evitar isso, deve-se levar em conta alguns efeitos escondidos, como a "Armadilha da Defasagem de Tempo", que será definida mais adiante neste artigo.

A metodologia pede a aplicação do modelo proposto em uma empresa real. Assim, uma indústria de magnésio é analisada. Esse é um segmento industrial bem consolidado, no qual, entretanto, inovações ainda estão sendo introduzidas, embora em um grau bem diferente do de empresas do setor de tecnologia da informação.

\section{Os passos da metodologia proposta}

Como exposto, a metodologia proposta deriva amplamente de conceitos de planejamento estratégico (Hax e Majluf, 1991) e de conceitos de Capital Intelectual. Essas duas áreas estão ligadas de uma forma em que é possível analisar a evolução do valor de mercado de uma empresa vis-à-vis a avaliação de seu Capital Intelectual ao longo do tempo. Os conceitos de estoque e fluxo de conhecimento são ambos importantes, porquanto capitais como o humano e o de inovação podem não alterar de forma síncrona a eficiência e a eficácia de uma empresa. $\mathrm{O}$ efeito assíncrono, a que 
tal Intelectual, o Capital Humano, o Capital de Inovação, o Capital de Processos e o Capital de Relacionamento de uma empresa, incluindo algumas modificações retiradas de simulações realizadas anteriormente.

\section{PROPOSTA DE MODELO PARA AVALIAÇÃO DE CAPITAL INTANGÍVEL}

Como relatado, deseja-se vincular a Estratégia Empresarial de uma empresa ao Capital Intelectual; assim, os fundamentos sobre os quais esse modelo será construído são expostos.

\section{- O âmbito da Estratégia Empresarial}

Ao rever a metodologia de formulação de Estratégia Empresarial de Hax e Majluf (1991), pode-se elaborar o diagrama mostrado na Figura 2.

A realização de cada Programa de Ação Específica (PAE ij) requer o estabelecimento de alguns indicado- res. Uma vez escolhidos, todos esses indicadores têm de ser representados em percentagem (\%). Naturalmente, alguns desses valores serão fornecidos ou como números absolutos ou como quantias em dinheiro. No entanto, há sempre uma maneira de converter esses valores em percentagens, seja pela divisão deles por outros valores, seja pela comparação com o melhor desempenho do setor, mediante uma análise de benchmark. Para fazer isso, utiliza-se a Data Envelopment Analysis. Essa metodologia procura as empresas que estejam desempenhando as melhores práticas, buscando identificar, com o resto mantido igual (por exemplo, para um determinado nível de produção), as empresas que atingem o melhor indicador de desempenho (Cubbin e Tzanidakis, 1998).

Da mesma forma, deve-se dar prioridade a cada Programa de Ação Específica (PAE ij). Utilizando-se a metodologia de Hax e Majluf (1991), três prioridades foram definidas: "Absoluta", "Altamente Desejável" e "Desejável".

Figura 2 - Modelo de Estratégia Empresarial

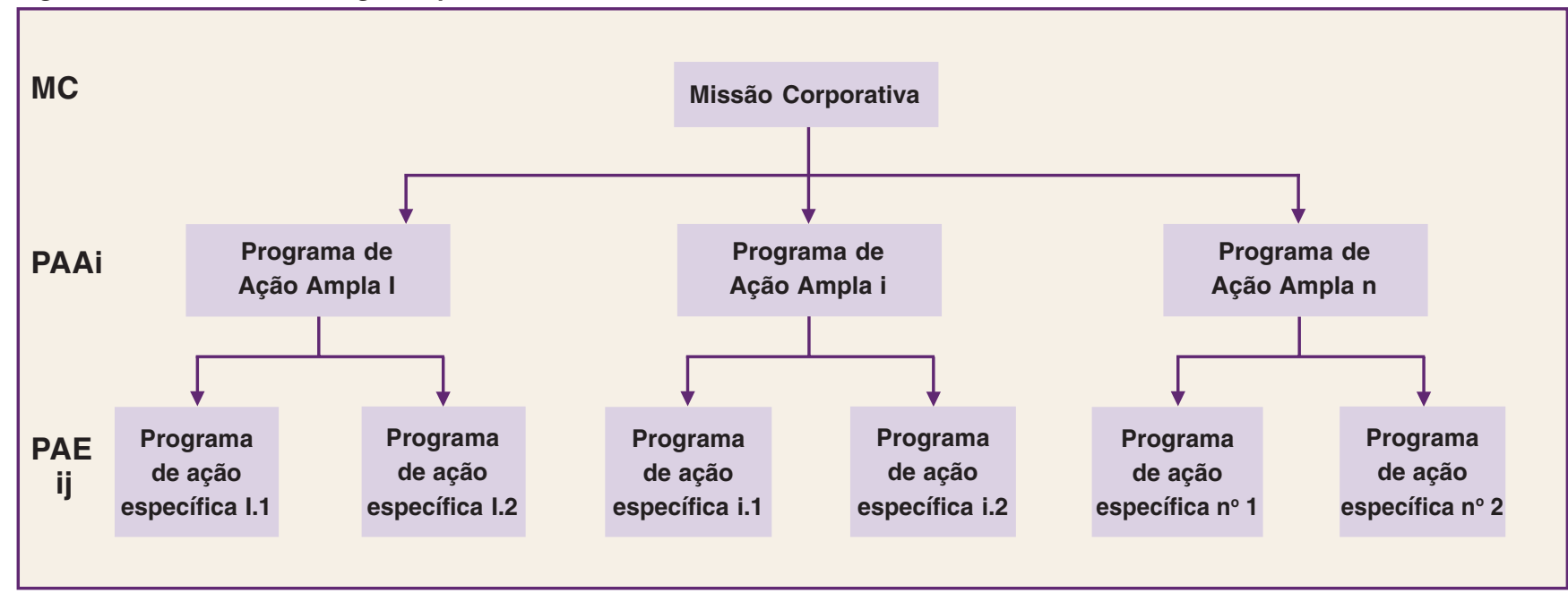

Figura 3 - Estrutura de Programa de Ação Específica

$\begin{aligned} & \text { Programa de Ação } \\ & \text { Específica PAE ij }\end{aligned}$
Prioridade (Pij)
$\begin{aligned} & \text { - Prioridade Primordialmente Absoluta (Pij }=3) \\ & \text { - Desejável (Pij }=1)\end{aligned}$
(Análise de Dados Próximos)
Benchmark


Como essas prioridades serão usadas mais adiante para calcular o Capital Intelectual consolidado, é preciso definir pesos para cada uma delas, como ilustra a Figura 3.

\section{- O âmbito do Capital Intelectual}

Como definido anteriormente, não há interesse em termos um valor absoluto para o Capital Intelectual, expresso basicamente em dólares norte-americanos, mas, ao contrário, devem-se acompanhar suas variações ao longo do tempo, assim como as de seus componentes. Os componentes do Capital Intelectual são: Capital Humano $(\mathrm{CH})$, Capital de Inovação (CI), Capital de Processos (CP) e Capital de Relacionamento (CR). Todos os indicadores estabelecidos anteriormente para cada Programa de Ação Específica são, então, classificados como pertinentes a algum componente do Capital Intelectual, de maneira que uma matriz de incidência para um ano específico $t-[\mathrm{W} t]-$ possa ser desenvolvida como mostramos na Tabela 2.

\section{- O Índice de Capital Intelectual}

Agora, é possível vincular o âmbito da Estratégia Empresarial ao do Capital Intelectual, a fim de avaliar os índices de capitais intangíveis para um ano específico $t$, pelo cálculo da média ponderada de cada capital. Assim, para cada ano $t$, tem-se:
- $\mathrm{CH} t=\sum(\% \mathrm{I} i j k) .(\mathrm{PCH} i j k) ;$ para $\quad(i=1, \mathrm{nPAA}$; $j=1, \mathrm{nPAE} ; k=1, \mathrm{n}$ indicadores)

- $\quad \mathrm{CP} t=\sum(\% \mathrm{I} i j k) .($ PCPijk); para $\quad(i=1, \mathrm{nPAA}$ $j=1, \mathrm{nPAE} ; k=1, \mathrm{n}$ indicadores)

- $\quad \mathrm{CR} t=\sum(\% \mathrm{I} i j k) .(\mathrm{PCR} i j k) ;$ para $\quad(i=1, \mathrm{nPAA}$; $j=1, \mathrm{nPAE} ; k=1, \mathrm{n}$ indicadores)

- $\quad \mathrm{CI} t=\sum(\% \mathrm{\%} i j k) .($ PCI $i j k) ;$ para $(i=1, \mathrm{nPAA} ; j$ $=1, \mathrm{nPAE} ; k=1, \mathrm{n}$ indicadores)

Ou, em linguagem matemática mais concisa e elegante:

\section{$[\mathrm{CH} t \mathrm{CP} t \mathrm{CR} t \mathrm{CI} t]=\{\mathrm{I}\}^{\mathrm{T}} \cdot[\mathrm{W} t]$}

em que $\{\mathrm{I}\}$ é o Vetor Indicador e $[\mathrm{W} t]$ é a Matriz de Incidência para o ano $t$.

É muito importante calcular todos esses capitais de forma consistente, para determinar o índice de Capital Intelectual (CI). Edvinsson e Malone (1997) sugerem que o Capital Intelectual é a média aritmé-

Tabela 2 - A Matriz de Incidência

\begin{tabular}{|c|c|c|c|c|c|c|c|c|}
\hline \multirow{2}{*}{$\begin{array}{c}\text { Programas } \\
\text { de Ações } \\
\text { Amplas } \\
\text { PAAi }\end{array}$} & $\begin{array}{l}\text { Programas } \\
\text { de Ações } \\
\text { Específicas }\end{array}$ & Prioridades & $\begin{array}{l}\text { Indicadores } \\
\text { (descrições) }\end{array}$ & $\begin{array}{c}\text { Ano } t \\
\text { (valores) }\end{array}$ & $\mathrm{CH} t$ & $\mathrm{CPt}$ & CRt & $\mathrm{Clt}$ \\
\hline & PAE $i j$ & Pij & lijk & $\begin{array}{c}(\%) \\
\% l i j k\end{array}$ & $\begin{array}{l}\text { (Pesos) } \\
\text { PCHijk }\end{array}$ & $\begin{array}{l}\text { (Pesos) } \\
\text { PCPijk }\end{array}$ & $\begin{array}{l}\text { (Pesos) } \\
\text { PCRijk }\end{array}$ & $\begin{array}{c}\text { (Pesos) } \\
\text { PClijk }\end{array}$ \\
\hline \multirow{11}{*}{ PAA1 } & \multirow{5}{*}{ PAE 11} & \multirow{5}{*}{$\begin{array}{l}\text { Altamente } \\
\text { desejável } \\
\text { (P11 = 2) }\end{array}$} & 1111 & $\% \mid 111$ & PCH111 & PCP 111 & PCR111 & $\mathrm{PCl} 111$ \\
\hline & & & 1112 & $\% 1112$ & PCH112 & PCP 112 & PCR112 & PCI112 \\
\hline & & & 1113 & $\% \mid 113$ & PCH113 & РCP 113 & PCR113 & $\mathrm{PCl} 113$ \\
\hline & & & 1114 & $\% 1114$ & PCH114 & PCP 114 & PCR114 & PCl114 \\
\hline & & & 1115 & $\% 1115$ & PCH115 & PCP 115 & PCR 115 & $\mathrm{PCl} 115$ \\
\hline & \multirow{6}{*}{ PAE 12} & \multirow{6}{*}{$\begin{array}{l}\text { Desejável } \\
\text { (P12 = 1) }\end{array}$} & 1121 & $\% 1121$ & PCH121 & PCP 121 & PCR121 & PCl121 \\
\hline & & & 1122 & $\% 1122$ & PCH122 & РCP 122 & PCR122 & PCI122 \\
\hline & & & 1123 & $\% 1123$ & PCH123 & PCP 123 & PCR123 & $\mathrm{PCl} 123$ \\
\hline & & & 1124 & $\%$ I124 & PCH124 & PCP 124 & PCR124 & $\mathrm{PCl} 124$ \\
\hline & & & 1125 & $\% 1125$ & PCH125 & PCP 125 & PCR125 & $\mathrm{PCl} 125$ \\
\hline & & & 1126 & $\% 1126$ & PCH126 & РCP 126 & PCR126 & $\mathrm{PCl} 126$ \\
\hline
\end{tabular}


tica de todos os seus componentes. Essa postulação não considera as prioridades $(\mathrm{P} i j)$ de cada indicador no Plano de Estratégia Empresarial, levando a resultados inadequados, como será observado no estudo de caso. Portanto, uma vez que é fundamental representar todos os impactos da Estratégia Empresarial no índice de Capital Intelectual, é necessário calcular a influência das prioridades do Programa de Ação em cada indicador de capital. O seguinte procedimento pode ser usado para um ano específico $t$ :

- P_CH $t$ (Prioridade Total associada ao Capital Humano $)=\sum(\mathrm{Pij}) .(\% \mathrm{PCH} i j k)$; para ( $i=1, \mathrm{nPAA} ; j=1, \mathrm{nPAE} ; k=1, \mathrm{n}$ indicadores)

- P_CPt (Prioridade Total associada ao Capital de Processo $)=\sum(\mathrm{Pi} j) .(\% \mathrm{PCP} i j k)$; para ( $i=1, \mathrm{nPAA} ; j=1, \mathrm{nPAE} ; k=1, \mathrm{n}$ indicadores)

- P_CRt (Prioridade Total associada ao Capital de Relações) $=\sum$ (Pij).(\%PCRijk); para ( $i=1, \mathrm{nPAA} ; j=1, \mathrm{nPAE} ; k=1, \mathrm{n}$ indicadores)

- P_CIt (Prioridade Total associada ao Capital de Inovação) $=\sum$ (Pij).(\%PCIijk); para ( $i=1, \mathrm{nPAA} ; j=1, \mathrm{nPAE} ; k=1, \mathrm{n}$ indicadores)

Então, o índice de Capital Intelectual para esse ano específico $(\mathrm{Ci} t)$ pode ser calculado assim:

$\mathrm{CI} t=(\mathrm{CH} t$. P_CHt $+\mathrm{CP} t$. P_CPt $+\mathrm{CR} t$. P_CRt + CIt . P_CIt $) /\left(\mathbf{P}_{-} \mathrm{CH} t+\mathbf{P}_{-} \mathrm{CP} t+\right.$ P_CRt + P_CIt $)$

\section{ESTUDO DE CASO NA INDÚSTRIA DE MAGNÉSIO}

Para verificar como o modelo proposto funciona na realidade, será analisado um caso em que a metodologia é aplicada. Nesse caso, o valor contábil e o valor de mercado da empresa observada (relação C/ M) são analisados de 1995 a 1998, em face dos índices de Capital Intelectual e seus valores componentes, assim como de sua Estratégia Empresarial. Algumas conclusões importantes podem ser observadas com base nessas comparações. Apesar de ser uma indústria consolidada, o setor de magnésio depende, fortemente, da inovação e, por conseqüência, do capital humano, à medida que novos processos precisam ser desenvolvidos mediante o uso intenso de tecnologia. Também é um setor que depende muito de energia e precisa amenizar seus impactos ambientais. Assim, embora não seja um setor baseado exclusivamente no conhecimento, como aqueles envolvidos com tecnologia da informação, algumas empresas continuam lutando para desenvolver novos conhecimentos baseados naqueles já empregados - característica principal da economia do conhecimento.

A empresa analisada, a que daremos o nome fictício de Magnex, tem uma participação estável no mercado de $15 \%$, abaixo de duas outras empresas com $37 \%$ e $16 \%$ do mercado, respectivamente. Seus principais produtos são lingotes, pó, folhas, placas e eletrodos forjados. A Magnex investe maciçamente na melhoria de sua tecnologia de processamento, para aumentar a produtividade das células eletrolíticas e reduzir seus custos. O crescimento do mercado de magnésio tem girado em torno de $6 \%$ ao ano, em virtude dos menores custos do magnésio, comparado ao alumínio e a outros metais.

\section{A Estratégia Empresarial da Magnex}

Usando os modelos de Industry Attractiveness e Business Strenght junto com o modelo SWOT, assim como a Estratégia de Crescimento Alternativo de Ansoff (1987), uma Estratégia Empresarial foi elaborada na forma abaixo:

a) Missão Corporativa: "Produzir produtos de alta qualidade, competitivamente, e vendê-los no mundo. O Marketing juntamente com o departamento de Pesquisa \& Desenvolvimento desenvolverão produtos adicionais e mercados com características de elevada elasticidade-preço para atingir lucratividade sustentável e melhorias no futuro."

b) Programas de Ação

Foram formulados Programas de Ação, assim como suas respectivas prioridades para a empresa (ver Tabela 3).

Um quadro detalhado dos índices de Capital Intelectual pode ser visto na Figura 4, e um gráfico demonstrando a evolução de $\mathrm{M} / \mathrm{C}$ ao longo do tempo na Figura 5, de forma a compararem-se os resultados.

\section{ANÁLISE DOS RESULTADOS}

Como mostrado anteriormente, só vale a pena fazer a medição do Capital Intelectual se existir algum vínculo com o valor acionário da empresa. Tampouco tem significado obterem-se valores absolutos; ao contrário, são as variações ao longo do tempo que podem levar a algumas conclusões a respeito da estratégia da empresa. 
Tabela 3 - Programas de Ação da Magnex

\begin{tabular}{|c|c|c|}
\hline Programas de ação abrangente & Programas de ação específica & Prioridade \\
\hline \multirow{2}{*}{ Alcançar baixo custo de produção } & Ganhos tecnológicos no processo & $\begin{array}{c}\text { Altamente desejável } \\
(\text { peso }=2)\end{array}$ \\
\hline & $\begin{array}{l}\text { Ganhos em eficiência nas } \\
\text { funções e métodos }\end{array}$ & $\begin{array}{l}\text { Desejável } \\
(\text { peso = 1) }\end{array}$ \\
\hline \multirow{2}{*}{$\begin{array}{l}\text { Desenvolvimento do } \\
\text { mercado de magnésio }\end{array}$} & Penetração de mercado & $\begin{array}{c}\text { Absoluta } \\
(\text { peso }=3)\end{array}$ \\
\hline & Desenvolvimento de mercado & $\begin{array}{c}\text { Altamente desejável } \\
(\text { peso = 2) }\end{array}$ \\
\hline \multirow{2}{*}{$\begin{array}{l}\text { Assegurar posição } \\
\text { futura do negócio }\end{array}$} & Sustentabilidade energética & $\begin{array}{c}\text { Altamente desejável } \\
(\text { peso }=2)\end{array}$ \\
\hline & Redução de impactos ambientais & $\begin{array}{c}\text { Altamente desejável } \\
(\text { peso }=2)\end{array}$ \\
\hline
\end{tabular}

Com relação à Magnex, pode ser visto que existe uma boa correlação entre os índices de Capital Intelectual e os valores $\mathrm{M} / \mathrm{C}$, parcialmente por causa da inclusão das prioridades dos Programas de Ação, normalmente desconsideradas em outros modelos. Mais do que calcular o Capital Intelectual pela simples média aritmética dos outros índices de capital, como proposto por Edvinsson e Malone (1997), a influência das prioridades é crucial para obter-se uma boa correlação estatística. Se a metodologia de Edvinsson e Malone (1997) fosse aplicada, seriam obtidos os índices de Capital Intelectual e a respectiva correlação estatística expostos na Tabela 4.

\section{A "Armadilha da Defasagem de Tempo" (ADT)}

$\mathrm{O}$ entendimento correto da diferença entre estoque de conhecimento e fluxo de conhecimento é vital à percepção do que está ocorrendo em uma empresa. Com relação à Magnex, pode concluir-se que, apesar dos consideráveis investimentos nos Capitais Humanos e de Inovação, os Capitais de Processos e Relacionamento minaram o índice de Capital Intelectual como um todo. Esse comportamento não é nada raro. Normalmente, alguns trade-offs são feitos, levando a resultados diferentes daqueles previstos. Essa falta de investimento no desenvolvimento de processos internos mais eficientes e eficazes, além de um descaso com

Figura 4 - Índice de Capital Intelectual

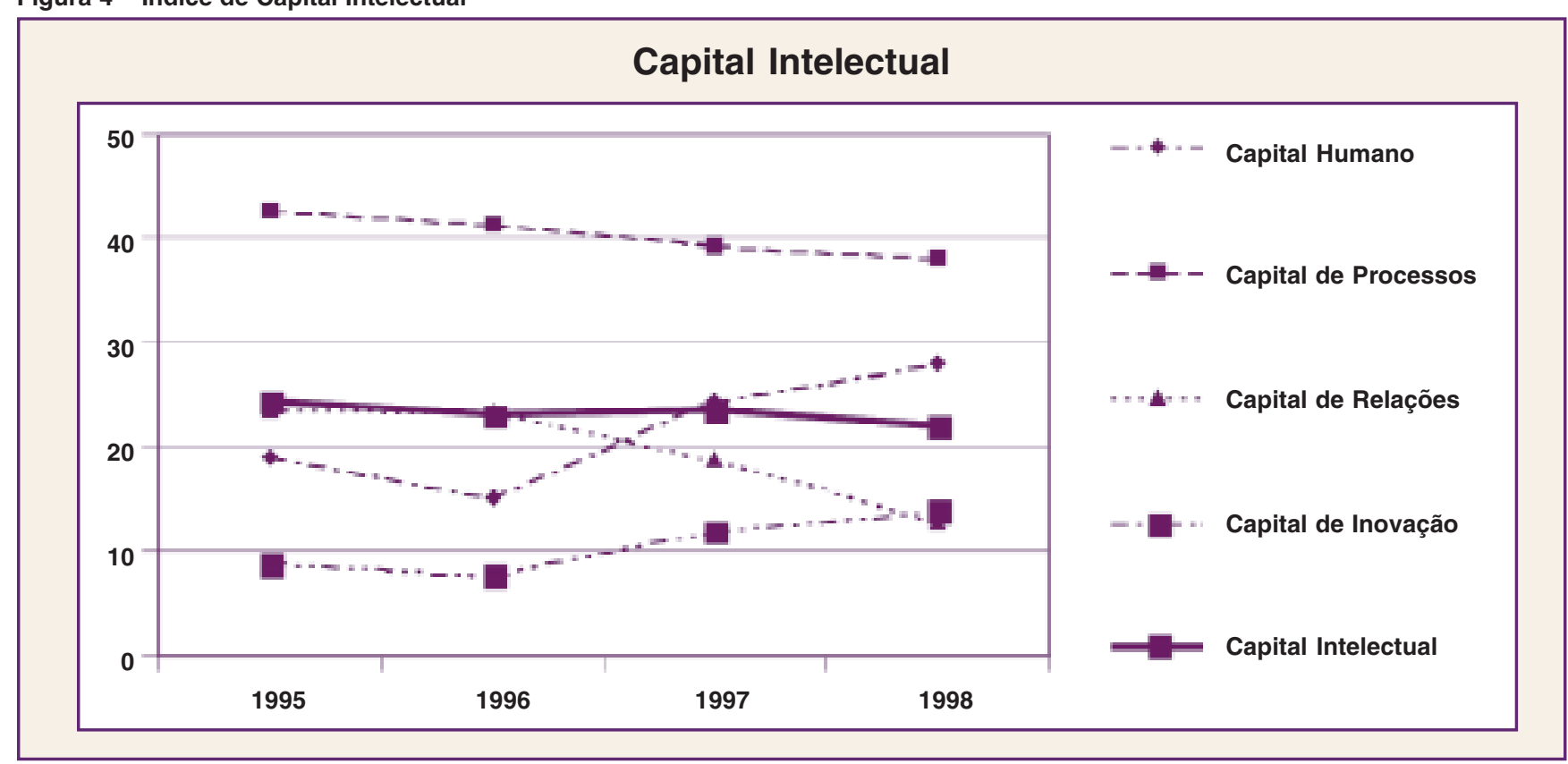


os parceiros da Magnex (clientes, fornecedores, bancos, etc.), pôs em risco a pontuação do Capital Intelectual. E mais: os efeitos dos pesados investimentos em Capital Humano e de Inovação levam algum tempo para ser plenamente sentidos, isto é, existe um tipo de "inércia ativa" (Sull, 1999) que retarda o emprego total e imediato dos benefícios derivados daqueles. A influência, tanto de um resultado alto como baixo, com relação aos Capitais de Processos e de Relacionamento, é rapidamente percebida pelo mercado, enquanto os Capitais Humano e de Inovação, como fontes de criatividade, requerem tempo para produzir resultados: um fenômeno que denominamos Armadilha da Defasagem do Tempo.

Um modelo dinâmico que leve em consideração esse efeito assíncrono tem de ser desenvolvido, uma vez que a maioria das pesquisas em andamento para avaliar o capital intangível não leva em conta o fator tempo como um parâmetro verdadeiramente importante. Assim, as mesmas objeções feitas aos métodos tradicionais de contabilidade podem ser aplicadas às metodologias recentemente desenvolvidas para medir o Capital Intelectual. O tempo é fator fundamental e tem de ser considerado em pesquisas futuras. Como exemplo, apresenta-se o valor de mercado da Magnex em julho de 1999 na Figura 6, na qual é possível ver que os benefícios do Capital Humano e de Inovação já foram percebidos pela mercado de capitais, levantando o valor de mercado da Magnex.

\section{CONCLUSÃO}

O ativo intangível é o núcleo da economia do conhecimento. O balanço de uma empresa pode representar um raio-X de como ela está hoje, mas não é ferramenta confiável para perceber seu desempenho num futuro próximo. Como Stewart (1997) relatou, os contadores são incapazes de medir o Capital Intelectual de uma empresa. E esse tesouro escondido é hoje o que realmente importa em uma sociedade em constante ebulição. O conhecimento substituiu a terra, o trabalho e o capital como o insumo de empresas baseadas no conhecimento. Apesar dos avanços feitos na compreensão da natureza do conhecimento - tanto tácito como explícito - e seus mecanismos de transferência dentro de uma empresa (Nonaka e Takeuchi, 1995) e entre seus parceiros (Badaracco, 1991), ainda há um longo e árduo caminho de negociação antes que se possa ter medições confiáveis para esse capital intangível. De acordo com Prusak (1997), a globalização da economia, o valor do conhecimento especializado, a conscientização do conhecimento como um fator distintivo na produção e a computação em rede barata são as principais forças propulsoras dessa revolução.

Figura 5 - Valores M/C da Magnex

\section{Valores de mercado/contábil}

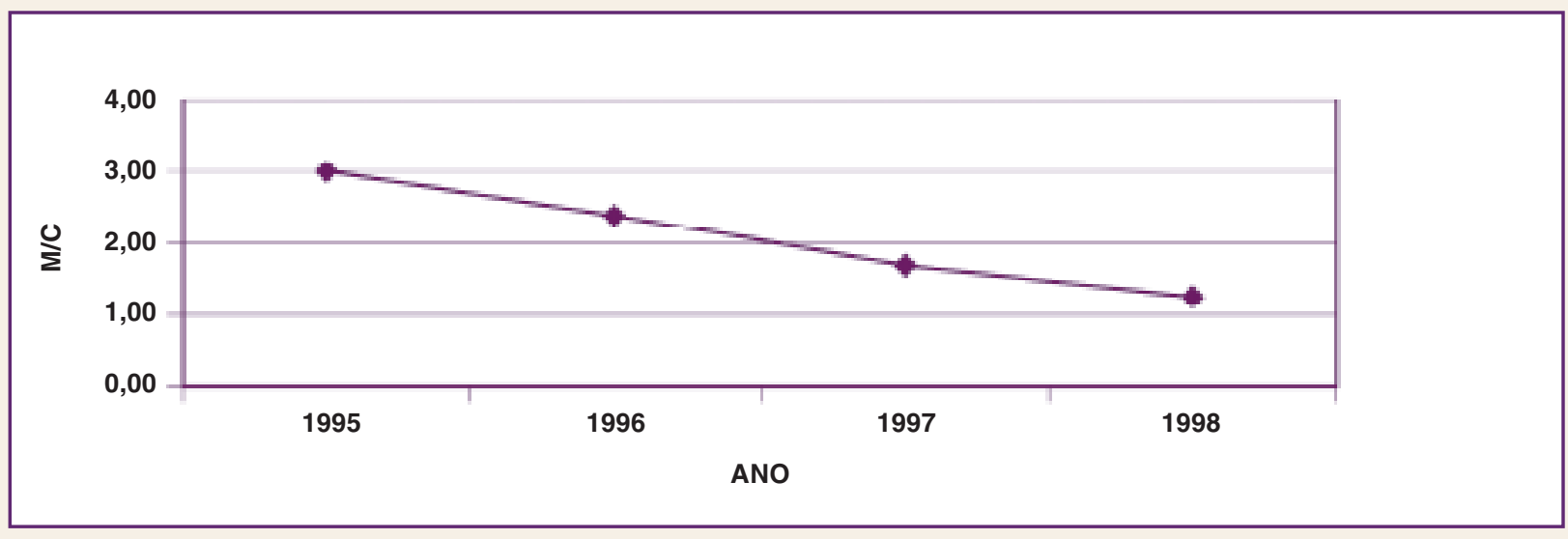

Tabela 4 - Comparação da correlação estatística

\begin{tabular}{|l|c|c|c|c|c|}
\hline Capital Intelectual & 1995 & 1996 & 1997 & 1998 & 23.26 \\
\hline $\begin{array}{l}\text { Edvinsson e } \\
\text { Malone }\end{array}$ & 23.57 & 21.94 & 23.69 & -0.206 \\
\hline Este modelo & 24.37 & 23.02 & 23.45 & 21.94 & 0.838 \\
\hline
\end{tabular}




\section{Valores de mercado/contábil}

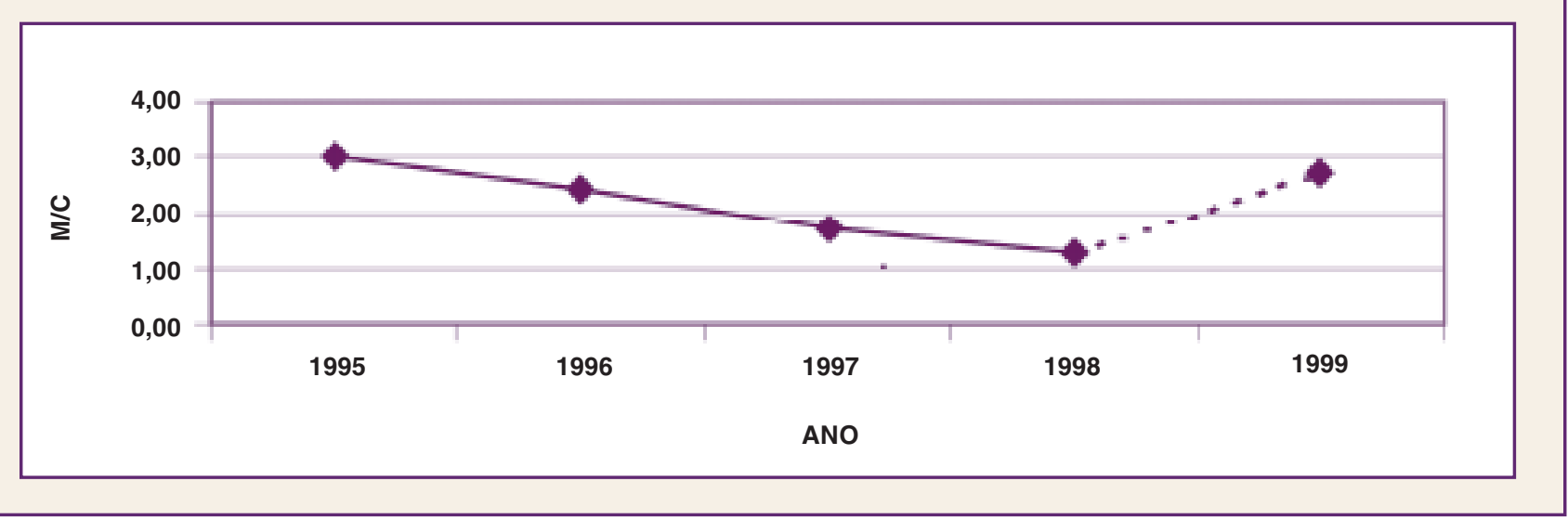

Outra faceta muito importante a ser pesquisada mais a fundo é o processo de depreciação do conhecimento da empresa. Argote et al. (1998) sugerem que existe um componente substancial de conhecimento organizacional que se deprecia rapidamente e indicam que mais pesquisa é necessária para identificar os fatores que estejam afetando a taxa de aprendizagem e "esquecimento" nas organizações. Yelle (1979) também sugere que a identificação dos fatores que favorecem uma taxa acelerada de aprendizagem é uma área promissora das pesquisas futuras. Essa compreensão pode superar a "Armadilha da Defasagem de Tempo" e permitir investi- mentos em treinamento e inovação que levem a resultados melhores e mais rápidos que os atingidos hoje. Finalmente, mais pesquisa é necessária ainda para entender a "Armadilha da Defasagem de Tempo" em setores diferentes, tanto nas empresas tecnologicamente desenvolvidas como nas baseadas no conhecimento.

Como visto, um modelo heurístico foi apresentado neste artigo e aplicado a um caso real, embora seja necessário mais estudo nesse campo muito recente e importante, de modo que se desenvolvam novos modelos para melhor entender o valor de um empreendimento como um todo. $\bigcirc$

\section{REFERÊNCIAS BIBLIOGRÁFICAS}

ANSOFF, H. I. Implanting strategic management. Englewood Cliffs, NJ : Prentice-Hall, 1984.

ANSOFF, H. I. Corporate strategy. Rev. ed. Bungay, Suffolk, UK : Penguin Books, 1987.

ARGOTE, L., BECKMAN S. L., EPPLE D. The persistence and transfer of learning in industrial settings. In: KLEIN, D. (Ed.). The strategic management of intellectual capital. Woburn, MA : Butterworth-Heinemann, 1998.

ARTHUR, W. B. Positive feedbacks in the economy. Scientific American, p. 80-85, Feb. 1990

ARTHUR, W. B. Increasing returns and the new world of business. Harvard Business Review, Boston, v. 74, n. 4 p. 100-109, July/Aug. 1996.

ARTHUR ANDERSEN AND THE ECONOMIST INTELLIGENCE UNIT. The valuation of intangible assets. London, 1992. Special Report, n. P254.

BADARACCO, J. The knowledge link: how firms compete through strategic alliances. Boston : Harvard Business School Press, 1991. Knowledge Links, chapter 5, p 107-128.

CUBBIN, J., TZANIDAKIS G. Techniques for analysing company performance. Business Strategy Review, v. 9 , n. 4, p. 37-46, Winter 1998
DRUCKER, P. Post-capitalism society. New York: HarperCollins Publishers, Inc., 1993.

EARL, M. Knowledge as strategy. In: PRUSAK, L. (Ed.). Knowledge in organisations. Woburn, MA : ButterworthHeinemann, 1997. p.1-15.

EDVINSSON, L., MALONE, M. Intellectual capital. New York HarperBusiness, 1997.

HAX, A. C., MAJLUF, N. S. The strategic concept and process. Englewood Cliffs, NJ : Prentice Hall, 1991.

HAYEK, F. The use of knowledge in society. The American Economic Review, v. 35, n. 4, p. 32-39, Sept. 1945

KAPLAN, R., NORTON, D. The balance scorecard. Boston : Harvard Business School Press, 1996.

KLEIN, D. The strategic management of intellectual capital: an introduction. In: KLEIN, D. (Ed.). The strategic management of intellectual capital. Woburn, MA Butterworth-Heinemann, 1998. p. 1-7.

NONAKA, I., TAKEUCHI, H. The knowledge-creating company: how Japanese companies create the dynamics of innovation. New York : Oxford University Press, 1995.
PRUSAK, L. Introduction to knowledge in organisations. In PRUSAK, L. (Ed.). Knowledge in organisations. Woburn, MA Butterworth-Heinemann,1997. p. ix-Xv.

R00S, J. et al. Intellectual capital. London : Macmillan Business, 1997.

STEWART, T. A. Intellectual capital. New York : Doubleday/ Currency, 1997

SULL, D. N. Why good companies go bad. Harvard Business Review, Boston, v. 77, n. 4, p. 42-52, July/Aug. 1999

SVEIBY, K. E. The new organisational wealth. San Francisco Berret-Koehler Publishers, Inc., 1997.

TOBIN, J. A general equilibrium approach to monetary theory Journal of Money, Credit and Banking, v. I, p. 15-29, 1969.

WINTER, S. Knowledge and competence as strategic assets. In: KLEIN, D. (Ed.). The strategic management of intellectual capital. Woburn, MA : Butterworth-Heinemann, 1998. p. $165-187$

YELLE, L. E. The learning curve: historical review and comprehensive survey, Decision Science, v. 10, p. 302-328, 1979. 